\title{
DAS NARRATIVAS: O PIBID E A FORMAÇÃO DE PROFESSORES PARA O TRABALHO COM O TEXTO EM SALA DE AULA
}

\section{FROM THE NARRATIVES: PIBID AND TEACHER EDUCATION TO WORK WITH}

\author{
THE TEXT IN THE CLASSROOM
}

HEINIG, Otilia Lizete de Oliveira Martins otilia.heinig@gmail.com FURB - Universidade Regional de Blumenau

\begin{abstract}
RESUMO O trabalho com leitura e produção de textos em sala de aula é a tônica deste artigo que visa analisar os dados provenientes da coleta inicial em outubro de 2011 que auxiliou no diagnóstico e consequente planejamento das ações em sala de aula. As narrativas são compreendidas pelo viés teórico da psicolinguística com amparo em Stein e Glenn (1979) e Scliar-Cabral e Grimm-Cabral (1984), o que auxilia na formação teórica dos professores, na produção de instrumentos de coleta e análise de dados e materiais didáticos. Para o diagnóstico da escrita dos alunos do ensino fundamental de três escolas, foram aplicados comandos para produção de narrativas que, depois de analisadas, nortearam as ações em sala de aula, as avaliações e novos diagnósticos ao final de cada ano. As narrativas iniciais indicaram que: a introdução da cena e personagens era escrita com expressões lingüísticas convencionais de início; havia uma situação problema e o resultado estava presente, mas não estava explicado como a situação problema foi resolvida. As ações dos professores em formação alteraram esses resultados iniciais, levandoos a compreender que um diagnóstico completo das narrativas permite entender quais são os principais problemas para tentar resolvê-los, o que exige um plano de trabalho em sala de aula durante todo o ano e uma intervenção com cada grupo de alunos para ajudá-los a refletir sobre o modo como organizam suas narrativas.
\end{abstract}

PALAVRAS-CHAVE: Formação de professores. Narrativas. PIBID. Sala de aula.

ABSTRACT Working with reading and text production in the classroom is the main topic of this article that aims to analyze the data from the initial collection in October 2011 that helped in the diagnosis and subsequent planning of actions in the classroom. The narratives are analyzed by the perspective of psycholinguistic of Stein; Glenn (1979) and Scliar-Cabral and Grimm-Cabral (1984), which help with the theoretical education of the teachers, with the production of instruments to collect data and with the data and didactic material analysis. To the diagnosis of students' writing from elementary school from three different schools, commands to the production of narratives were applied. These narratives, after analyzed, guided the actions in the classroom, the evaluations and new diagnostics at the end of each year. The previous narratives showed that: the introduction of the scenario and characters was written with common opening linguistic expressions; there was a problem and the result was present in the text, but there was no explanation about how the problem was solved. The action of the teachers in education altered these 
previous results, making the teachers to understand that a complete diagnostic of the narratives can allow them to know the main problems and try to solve them, what requires a plan to work in the classroom during all the year and an intervention with each group of students, helping them to reflect on the way they organize their narratives.

KEYWORDS: Teacher education. Narratives. PIBID. Classroom.

\section{INTRODUÇÃO}

A língua portuguesa como disciplina se articula em diferentes eixos que dialogam entre si: leitura, oralidade, análise linguística e produção de textos. Entretanto, a formação do professor acontece de forma isolada, pois cada disciplina trata de especificidade, raramente estabelecendo aproximações entre os eixos ou entre a teoria e a prática. Um dos pontos a se refletir é a avaliação da produção escrita que pouco tem sido contemplada na formação em serviço, deixando que esse conhecimento se dê na própria prática, ao ter contato com os textos dos alunos, seja no estágio ou no início da docência. Compreender o processo de avaliação diagnóstica e processual para poder planejar a ação docente e, partindo dela, realizar intervenções que sejam eficazes, é um dos focos da didática das línguas, da psicolinguística e linguística aplicada. Dentro dessa perspectiva, é que foi submetido à Coordenação de Aperfeiçoamento de Pessoal de Nível Superior (CAPES) e desenvolvido o subprojeto do Programa Institucional de Bolsa De Iniciação à Docência (PIBID) de Letras da Universidade Regional de Blumenau (FURB) que visou, principalmente, estudar os princípios de organização do sistema de escrita no nível do texto para que o graduando compreenda a base teórica que permitirá uma ação mais sólida sobre a demanda encontrada na realidade escolar. Neste artigo, o objetivo é analisar os dados provenientes da coleta inicial em outubro de 2011, que auxiliou no diagnóstico e consequente planejamento das ações para o final de 2011 e 2012.

Em um momento em que os gêneros discursivos são a tônica nos documentos oficiais, alguns podem se perguntar por que discutir narrativas. Primeiro, porque o estudo do eixo do narrar permite um conhecimento da estrutura em seus aspectos globais, servindo, posteriormente, para ancoragem dos estudos dos gêneros que apresentam características em comum. Segundo, porque a maioria 
das pesquisas nessa área investigaram narrativas orais. Além disso, os sujeitos participantes dessas pesquisas são crianças entre cinco e doze anos. No estado da arte produzido, encontramos estudos sobre narrativa ficcional e pessoal (PREECE, 1987; GHEZZI et al., 1987; BAMBERG, 1994; BERMAN, 1995; SHIRO, 2003); narrativas orais (HUDSON; SHAPIRO, 1991; BERMAN; SLOBIN, 1994; SPINILLO; PINTO, 1994) e narrativas escritas (REGO, 1985; 1986; BUARQUE et al., 1992; LINS E SILVA; SPINILLO, 1998). Este último é importante para o nosso estudo, pois apresenta uma classificação para as narrativas coletadas. Analisando as pesquisas desenvolvidas, observaram-se duas lacunas, uma diz respeito a estudos sobre narrativas escritas e outra quanto a narrativas escritas por adolescentes, o que justifica a investigação realizada.

No que tange à formação de professores, como afirma Tardif, é preciso haver uma articulação entre teoria e prática, permitindo que a formação aconteça de forma dialógica, o que vem sendo oportunizado pelo PIBID:

Os cursos de formação para o magistério são globalmente idealizados segundo um modelo aplicacionista do conhecimento: os alunos passam um certo número de anos a assistir a aulas baseadas em disciplinas e constituídas de conhecimentos proposicionais. Em seguida, ou durante essas aulas, eles vão estagiar para "aplicarem" esses conhecimentos. Enfim, quando a formação termina, eles começam a trabalhar sozinhos, aprendendo seu ofício na prática e constatando, na maioria das vezes, que esses conhecimentos proposicionais não se aplicam bem na ação cotidiana. (TARDIF, 2002, p. 270).

A discussão que o artigo propõe permite ao professor em formação avaliar textos reais o que vai além de uma aplicação de conhecimento, exige a sua mobilização para uma prática pedagógica.

O texto foi organizado a fim de que se possa conhecer as relações entre as ações desenvolvidas no subprojeto anunciado, o estudo das bases teóricas sobre narrativas (STEIN; GLENN, 1979; SCLIAR-CABRAL; GRIMM-CABRAL, 1984), a metodologia de coleta de dados de escrita e sua análise para que se possa também discutir a formação de professores para a avaliação diagnóstica de textos do eixo do narrar a fim de intervir no processo de ensino e aprendizagem da escrita. 


\section{O SubPROJETO: INTENÇÕES, Plano de tRABALHO, OBJetivos E AÇÕES PREVISTAS}

Em 2011, um desafio se apresentou: produzir o subprojeto de Letras para ser submetido ao EDITAL № 001/2011/CAPES. Com tantas veredas a serem desbravadas, era preciso escolher um caminho, então, optou-se por trabalhar com narrativas em uma perspectiva mais ampla, ou seja, a que contemplasse o eixo do narrar. A ideia era, a partir disso, desenvolver um trabalho com os gêneros discursivos desse eixo como a fábula, os diversos contos, os poemas narrativos, as crônicas, as histórias em quadrinhos, as memórias, entre tantas possibilidades. Esse era, no primeiro momento, o que se projetava, mas entre o subprojeto e a realidade, novos encontros ocorreram, pois nem sempre o que se idealiza representa o real vivido.

A elaboração do subprojeto, a seleção das escolas, o desenho da metodologia, tudo estava ali no papel, aguardando uma resposta positiva por parte da Capes. Dizer o que se pretende em um espaço sintético como o do subprojeto foi o primeiro desafio, aliás, a língua escrita, núcleo do que nos levou a apresentar a proposta, é o que nos move há muito em nossa atuação junto a alunos e professores. Muitos se queixam que têm dificuldade de escrever, outros que seus alunos escrevem mal, há também os que estão entre as mudanças teóricometodológicas e não entendem bem o que significa trabalhar com gêneros do discurso, qual a diferença entre redação e produção de texto e onde ficou a tipologia textual. São mesmos muitos os desafios que se impõem.

Para que se possa compreender as ações que foram previstas e desenvolvidas ao longo dos quase três anos de atuação nas escolas, apresentamos o plano de trabalho e a sua proposta. São objetivos que nortearam o trabalho quando os atores educacionais envolvidos se viam diante de um cenário complexo em relação à produção escrita dos alunos. Para conhecimento do leitor, enumeramos as dez ações norteadoras: 


\begin{abstract}
estudar os princípios de organização do sistema de escrita no nível da palavra e do texto para que o graduando compreenda a base teórica que permitirá uma ação mais sólida sobre a demanda encontrada na realidade escolar; elaborar proposta de produção de textos a ser aplicada junto aos alunos do ensino fundamental; aplicar proposta de produção de textos junto às escolas parceiras do subprojeto; analisar as produções escritas de alunos do ensino fundamental a fim de verificar as principais facilidades e dificuldades encontradas na produção textual; retomar e ampliar as bases teóricas de formação para a atuação na área de revisão, avaliação e análise de textos produzidos por alunos do ensino fundamental; analisar materiais didáticos existentes que auxiliem na aprendizagem do sistema de escrita no nível da palavra e do texto; produzir e/ ou adequar materiais pedagógicos que auxiliam a aprendizagem das comunidades investigadas levando o professor em formação a articular teoria, conhecimento dos grupos e metodologia de ensino; aplicar junto à comunidade escolar os materiais desenvolvidos fazendo observação do seu uso em sala de aula a fim de compreender como esses podem interferir no processo de aprendizagem; descrever os procedimentos observados no espaço da sala de aula, aliando à base teórica previamente estudada a fim de compreender as relações teoria-aplicação; socializar com os demais professores em formação as aprendizagens vivenciadas no processo de estudo e aplicação de materiais sobre os princípios de organização de escrita (FURB, 2011, p. 1-2).
\end{abstract}

Para que essas ações fossem executadas, foi necessário também selecionar o lócus de atuação. Como os demais projetos do PIDIB da FURB até aquele ano estavam em Blumenau, optou-se por selecionar escolas de outros municípios, mas que também são atendidos pela universidade seja pela formação continuada seja pela formação em serviço tendo em vista que essa Instituição de Ensino Superior recebe acadêmicos de vários municípios da região do Vale do Itajaí. Um dos critérios foi a análise do Índice de Desenvolvimento da Educação Básica (IDEB) das escolas e outro a disponibilidade de um professor efetivo que pudesse realizar o trabalho.

Para alcançar o que se delineou no subprojeto, algumas medidas foram planeadas e, posteriormente, executadas. Entre elas, gostariamos de destacar: formação teórica do professor em formação no que concerne ao sistema de escrita e organização textual: neste aspecto, os bolsistas Iniciação à Docência (ID) estudaram a teoria dos esquemas tanto teoricamente bem como realizaram a análise de filmes e textos a fim de compreender a lógica organizacional da narrativa. Outra etapa prevista foi a produção de diagnóstico que possibilitasse o levantamento de facilidades e dificuldades de escrita de alunos do ensino fundamental, o que será 
detalhado na seção de análise. Este trabalho foi o que viabilizou um planejamento detalhado de cada ação junto aos grupos de alunos, atendendo às necessidades de cada turma e escola. Também serviu de material empírico para a produção de artigos científicos que foram sendo socializados em eventos e periódicos. A análise dos problemas textuais de produções escritas de alunos matriculados no ensino fundamental, foco deste artigo, é a base para que o professor em formação identifique as dificuldades de acordo com o nível de escrita do grupo e proponha atividades e produza materiais para o ensino e aprendizagem da escrita. Por fim, o trabalho possibilitou a aproximação entre a universidade e a escola de ensino básico a fim de identificar as necessidades no que concerne à língua portuguesa e promover uma formação adequada.

\section{A BASE EPISTEMOLÓGICA DAS NARRATIVAS: ANCORANDO AS PRÁTICAS}

Há muitos vieses teóricos sob os quais um estudioso pode se debruçar para compreender a organização das narrativas, uma prática tão comum entre todos os povos, a qual serviu para garantir ensinamentos e a própria sobrevivência. Em nosso subprojeto, optamos pelos estudos com base na psicolinguística no que tange à representação mental de textos e discursos. Nesta perspectiva, as narrativas são compreendidas como mais do que um caminho para comunicar nossas experiências, são uma maneira de entendermos a nossa vida e a nós mesmos. Assim, as experiências ganham sentido e ajudam a construir o mundo a nossa volta. (BRUNER, 2004; FIVUSH; HADEN, 1997).

As narrativas podem ser classificadas em factual, que emergem mais cedo (SCLIAR-CABRAL; STOEL-GAMMON, 1976; FIVUSH; HADEN, 1997), e ficcional cuja estrutura é mais complexa (CÂNDIDO et al., 1968) e para a qual há uma seleção de esquemas. Segundo McCabe et al. (2008, p 194), "o termo narrativa pode e tem sido aplicado a vários gêneros, especialmente narrativas pessoais e às ficcionais ou faz de conta"1. A característica principal de uma narrativa é a relação de causalidade a qual é discutida por Mar (2004, p. 1415):

\footnotetext{
${ }^{1}$ The term narrative can and has been applied to various genres, especially personal narratives and fictional or make-believe ones.
} 


\begin{abstract}
Uma característica fundamental das histórias é a presença de um evento de estrutura causal. Na sequência de uma distinção por Graesser, Hauft-Smith, Cohen, e Pyles (1980), uma apresentação narrativa pode ser pensada como a descrição de uma série de ações e eventos que se desenrolam ao longo do tempo, de acordo com os princípios causais. Estas regras de causalidade exigem que os eventos ocorram obrigatoriamente em uma ordem lógica e coerente. Episódios e ações que permitem a outros eventos devem ter precedência temporal, dada a fusão da lógica (se $x$ então $y$ ), causal (porque $x$ então $y$ ), e prioridade temporal (primeiro $x$ então $y$ ) encontrados em narrativas (Barthes, 1982; Dixon, 1996) ${ }^{2}$.
\end{abstract}

De acordo com Scliar-Cabral (1991), os esquemas ou gramáticas das estórias são teorias que procuram dar conta de como o conhecimento de mundo é representado em nossa memória de modo a explicar a forma como compreendemos as narrativas.

O fato de compreendermos narrativas novas se deve a dois aspectos importantes: primeiro, as narrativas devem obedecer a uma estrutura canônica subjacente que se conformaria ao modo como percebemos e conhecemos o desenrolar dos acontecimentos no espaço e no tempo; segundo, as categorias e seus elos vêm formalizados em sistemas semióticos (sistema verbal, neste estudo) e por isto, a internalização dos esquemas ou gramáticas das estórias depende de as crianças estarem expostas a experiências narrativas.

Na situação de reconto, de uma versão diferente de uma estória já conhecida, a criança tende a preservar a versão internalizada. Mesmo assim, podemos dizer que o campo para a criatividade é vasto sendo mantidos os esquemas narrativos, que caracterizam o gênero e o conteúdo narrado, ou seja, a estória stricto sensu.

Os estudos sobre os esquemas foram avançando a partir de Bartlett (1932) para quem a recordação narrativa é altamente organizada e relembrar é uma reconstrução imaginária. Além dele, Schank (1975), ao estudar os esquemas narrativos, assevera que a sentença dá informação e significado, estabelecendo condições de coerência para a frase seguinte o que permite que um parágrafo seja

\footnotetext{
${ }^{2}$ One fundamental characteristic of stories is the presence of a causal event-structure. Following a distinction by Graesser, Hauft-Smith, Cohen, and Pyles (1980), a narrative presentation can be thought of as the description of a series of actions and events that unfold over time, according to causal principles. These rules of causation demand that events occur in a constrained, logically coherent order. Episodes and actions that allow for other events must take temporal precedence given the conflation of logical (if $x$ then $y$ ), causal (because $x$ then $y$ ), and temporal priority (first $x$ then $y$ ) found in narratives (Barthes, 1982; Dixon, 1996).
} 
definido como um conjunto de cadeias causais, estabelecidas tanto por sentenças explícitas, como por inferências. Simultaneamente, há os estudos de Rumelhart (1975) nos quais as histórias têm uma estrutura interna bem como regras sintáticas e regra semântica correspondente.

Utilizamos, em nosso estudo, o modelo de Stein e Glenn (1979) que tem com escopo sustentar os processos que permitem a seleção de determinadas partes das estórias a serem recordadas em detrimento de outras dentro da compreensão de um texto, os quais não são explicados em nível de processamento de palavras ou sentenças isoladas. Os referidos autores reportam-se a Bartlett (1932) a fim de enfocar a definição de esquema. Assim sendo, esquema é concebido como uma organização ativa das reações e experiências passadas que estão continuamente operando em qualquer organismo bem desenvolvido.

Para organizar um certo modelo de compreensão, é necessário abarcar um conjunto de regras que definem os tipos de unidades informativas e os tipos de relações que existem entre elas. A delimitação da unidade de análise é o primeiro passo para a confecção do modelo de compreensão. Segundo Stein e Glenn (1979), no esquema das estórias, existe uma estrutura interna semelhante à das sentenças e uma rede hierárquica de categorias e de relações lógicas entre essas categorias.

Para uma compreensão de como estão organizadas as regras de Stein e Glenn, apresentamos abaixo o seu esquema:

Figura 1: Regras que definem a representação interna de uma estória

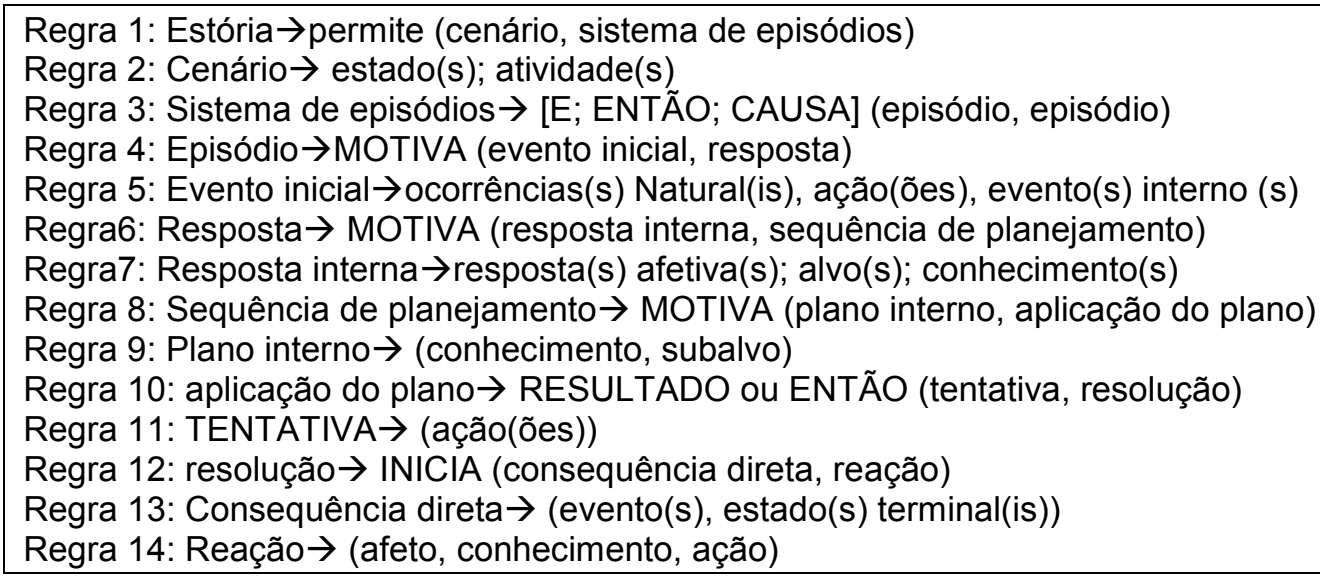


A primeira regra estabelece que a estória permite ao cenário ser condição para o desenvolvimento do sistema de episódios. O cenário introduz os personagens, na forma de seus estados ou atividades (regra 2). A característica dos estados e atividades é sua habitualidade e caráter de permanência, ao contrário dos episódios, essencialmente dinâmicos. A regra 3 formaliza a eventualidade de mais de um episódio no esquema da estória. Portanto as relações interepisódicas vêm formalizadas. O episódio é definido como consistindo de uma sequência comportamental completa, incluindo tanto eventos internos quanto externos, os quais terão como consequência uma resposta (regra 4). O evento inicial pode ser considerado como fator desencadeador da intriga e tanto pode se constituir de uma ocorrência da natureza, de uma ação, quanto de um evento interno (regra 5). A resposta estabelece o elo entre uma resposta interna (o estado psicológico do personagem) e a sequência (regra 6). A resposta interna pode ser do tipo afetivo (alegria, tristeza), ou revelar as intenções do personagem, ou sua intelecção dos fatos (regra 7). O plano interno motiva a aplicação do plano, o que vem formalizado na regra 8. O plano interno, em geral, omitido nas estórias de crianças mais novas, consiste em intelecções ou intenções intermediárias para obtenção do alvo principal (regra 9). O esforço conduz o estado de desequilíbrio à resolução, durante a aplicação do plano e aparece como comportamento em aberto (regra 10). A tentativa se manifesta através de ações, enquanto a resolução corre através de uma reação desencadeada por uma consequência direta (regras 11 e 12). As consequências diretas podem ser ocorrências naturais, ações ou estados finais (regra 13). A última regra (14) formaliza as reações afetivas, cognitivas e as ações do personagem, como resultado de uma consequência direta.

O modelo de Stein e Glenn (1979) foi reformulado por Scliar-Cabral e GrimmCabral (1984). As autoras introduziram duas regras para darem conta da instauração do fictício que caracteriza como a criança selecionará, entre os esquemas correspondentes aos vários gêneros de textos, o esquema do conto de fadas. Este gênero se caracteriza pela suspensão do tempo e aspecto factuais em favor de um tempo e espaço fictício, bem como de uma entoação peculiar, marcada por diferenças de chaves bem contrastivas. Essas propriedades foram formalizadas 
através de símbolos categoriais, uma vez que são inerentes ao gênero da narrativa do conto de fadas e perpassam todo o texto.

A segunda regra introduz as fórmulas mágicas inicial e de encerramento, na forma de um símbolo descontínuo, marcando o início e o fim do conto de fadas, quando os interlocutores são devolvidos ao factual. A regra 1 de Stein e Glenn passa a ter o número 3 e assim por diante. A regra 4 foi acrescida da categoria contexto e da referência explícita aos personagens. Considerou-se que o estado dos personagens, seus atributos permanentes não são da mesma natureza que o ambiente onde vivem, ou onde se desenrolam os episódios. A regra 5 recebeu o acréscimo do símbolo recursivo cenário, o qual pode ser inserido em qualquer desenvolvimento dos episódios. As regras de limite são acrescentadas. A primeira delas refere-se à necessidade de formalizar os nexos que conectam a ocorrência de mais de uma categoria no escopo da mesma regra (regra 1). Foi necessária a formalização das regras de coesão e de coerência que se referem à anáfora, elipse e coesão semântica (regras 2 e 3). Além disso, introduziu-se a Regra de Limite 4 para garantir a progressão da estória (fio narrativo). Stein e Glenn (1979) não mencionam a existência do drama no conto de fadas, por isso Scliar-Cabral e Grimm-Cabral (1984) incorporam a regra opcional.

Figura 2: Regras reformuladas por Scliar-Cabral e Grimm-Cabral

1. Conto de Fadas $\rightarrow$ PERMITE (Fictício (+ entoação do conto,+Espaço e tempo não factuais) Estória
2. Fictício (+ entoação do conto,+ espaço e tempo não factuais) $\rightarrow$ Fórmula inicial... de encerramento
3. Estória $\rightarrow$ PERMITE (cenário, sistema de episódios)
4. Cenário (estado(s), atividade(s) do personagem, contexto(s))
5. Sistema de episódios $\rightarrow$ [E, ENTÃO, CAUSA] $\rightarrow$ episódio(s) cenário(s) FONTE: (SCLIAR-CABRAL, 1991)

As regras que seguem são denominadas de limite: Regra 1: categorias repetidas dentro de um mesmo constituinte deverão vir ligadas pelas relações $E$, ou Então, ou Causa. Regra 2: dêiticos, pronomes e morfemas que assinalam concordância e/ou definição devem referir-se a enunciados precedentes, exceto quando ligadas a um modificador ou qualificativo. Regra 3: os substitutos semânticos devem referir-se a itens lexicais precedentes ou subsequentes. Regra 4: as regras 1,2 (parcialmente), 3,4,6,7,8 e 10 (parcialmente), 12 e 14 (parcialmente) são 
obrigatórias. Regra opcional: qualquer ação poderá ser preenchida por discurso direto ou indireto.

As regras permitem analisar narrativas a fim de observar como o autor do texto oral ou escrito articula as diferentes partes entre si, se todas se fazem presentes, se há uma relação de causalidade entre as partes do texto, como a parte inicial e final são costuradas ao longo dos episódios. Esse conhecimento pode permitir ao professor avaliar as produções de seus educandos, promovendo um planejamento que Ihes permita ler analiticamente uma narrativa e, posteriormente, possa produzir um texto coeso, coerente e com observância das regras.

\section{O CAMINHO METODOLÓGICO}

Ainda que o ponto central desse artigo seja a análise das narrativas iniciais, optamos por contextualizar o processo de formação e atuação dos bolsistas e supervisores que, no primeiro momento do subprojeto, produziram conhecimento teórico sobre narrativas através de leituras, minicursos, análise de textos narrativos e de filmes. Posteriormente, houve a visita às escolas para reconhecer e analisar o ambiente de letramento escolar.

Para conhecer a produção escrita dos alunos do ensino fundamental das escolas envolvidas no subprojeto de Letras, optamos pela aplicação de proposta de produção de textos. A primeira, que deu origem ao corpus aqui analisado, ocorreu no início do subprojeto, na primeira semana de outubro de 2011 , com o objetivo de diagnosticar a escrita de narrativas. Outras avaliações foram realizadas, uma, no final do ano de 2012, a fim de avaliar o impacto das ações realizadas em sala de aula nos textos narrativos dos alunos; outra ao final de 2013 , objetivando analisar as aprendizagens acerca do gênero discursivo do eixo do narrar trabalhado em cada turma.

Os 164 alunos dos anos finais do ensino fundamental das três escolas participantes receberam a proposta de produção escrita individualmente e, na folha entregue, além da sequência de cinco cenas, constava a seguinte orientação: Prezado (a) aluno (a), gostaríamos de contar com a sua colaboração em um 
trabalho que estamos desenvolvendo. A sua tarefa é simples. Primeiro, analise os quadros da história e depois crie uma história que narre o que está acontecendo. Não se esqueça de colocar um título. Muito obrigado por sua colaboração. Vale salientar que essa proposta já havia sido aplicada, no semestre anterior, por alunos do sétimo semestre do curso de Letras junto a alunos do sexto ano do ensino fundamental e foi facilmente compreendida pelos estudantes, validando, assim, o instrumento de coleta de dados. Na proposta, não houve delimitação do gênero a ser produzido, deixando a escolha por conta do produtor do texto, pois o objetivo era analisar se havia a internalização do esquema narrativo e que gêneros seriam eleitos pelos participantes para a materialização de seu enunciado.

Depois de produzidos, os textos foram digitados mantendo a escrita do aluno a fim de que se pudesse iniciar a avaliação das narrativas as quais foram analisadas considerando dois aspectos fundamentais: a) o esquema de Stein e Glenn (descrito anteriormente); b) a coesão textual. Desse trabalho, surgiram dois materiais: as narrativas dentro do esquema narrativo e as tabelas, por turma, considerando aspectos da gramática de estória e da coesão textual.

Ao realizarem a análise das narrativas e, posteriormente, organizarem os dados em tabelas, os acadêmicos de Letras envolvidos no subprojeto produziram um diagnóstico de cada turma. Esse material foi fonte para: o planejamento das aulas ao longo do desenolvimento do subprojeto; formação continuada junto aos professores e acadêmicos; produção de artigo científico; socialização em eventos científicos. Entretanto, tendo em vista o recorte que se faz necessário, neste artigo, iremos analisar a produção inicial, deixando indicadores dos aspectos a serem considerados nas demais ações do subprojeto.

\section{OS TEXTOS DOS ALUNOS: UM OLHAR PARA A ESCRITA NO PROCESSO INICIAL DO SUBPROJETO E RUMOS PARA A AÇÃO EM SALA DE AULA}

O processo de escrita não pode ser capturado em um texto, mas ele traz em si marcas de aprendizagens ocorridas ao longo do período escolar, sinaliza as construções realizadas em torno do que é ler e escrever e, em nosso caso, indica as fragilidades que devem ser contempladas no planejamento escolar a fim de que, 
mobilizando conhecimentos já adquiridos e refletindo sobre as necessidades de cada texto em cada turma, o professor possa avançar na escrita de narrativas que contemplem uma estrutura que seduza o leitor.

A tarefa de mapear as dificuldades em um número de textos como os do momento inicial deve ser feita com cautela e orientação tanto para formar o professor a produzir um diagnóstico adequado quanto ao padrão de aproximação dos dados de diferentes turmas e escolas. Para tal, a proposta foi o levantamento de dados por turma considerando as mesmas categorias conforme descrito na seção anterior.

A análise inicial dos 164 textos apontou, dentre vários aspectos, especialmente, para cinco dificuldades dos estudantes: distinção entre diferentes gêneros discursivos, estrutura da narrativa, coesão textual, relação de causa e consequência, ortografia. Os quatro primeiros foram foco de ações específicas juntos aos alunos e o último permeou o trabalho durante o tempo de atuação do projeto. No que segue, iremos analisar os problemas já anunciados, tendo em vista que esse foi o passo para um trabalho junto aos participantes do subprojeto, mas que também pode servir de inspiração para outros educadores e pesquisadores no que tange a conhecer como escrevem os alunos do ensino fundamental para poder dialogar e intervir colaborativamente.

No que diz respeito ao gênero discursivo, observou-se que $57 \%$ das narrativas começam com "era uma vez", a fórmula inicial, presente na regra 2 de Scliar-Cabral e Grimm-Cabral (1984), que caracteriza como a criança selecionará, entre os esquemas correspondentes aos vários gêneros, o esquema do conto de fadas. Entretanto, os textos produzidos pelos estudantes não são contos de fada. Ao analisar inícios como: "Era uma vez um menino que adorava cuidar da natureza," opção de um estudante de 12 anos da 6 . $^{\text {a }}$ série $^{3}$ e "Era uma vez João num belo dia de sol resolveu plantar alguns pés de arvores" "4, a abertura do texto de um estudante de 15 anos, cursando a $7 .^{a}$ série, percebe-se que não é a distinção de série ou idade que justifica esse início. Uma das possíveis explicações para esse início de texto é que a internalização de gêneros discursivos como o conto de fadas

\footnotetext{
${ }^{3}$ No momento da coleta dos dados, as escolas participantes ainda adotavam a organização por séries nos anos finais.

${ }^{4} \mathrm{~A}$ redação dos alunos não sofreu correção.
} 
(ou maravilhosos) acontece na primeira infância e que, posteriormente, ela é arraigada durante a vida escolar, através do trabalho com gêneros dos quais as crianças participam. A partir do momento em que uma pessoa entra em largo contato com um gênero, ela acaba criando uma relação de condição desse gênero, por isso o estudante produz os textos com os quais está familiarizado.

No campo das finalizações das narrativas, uma característica recorrente, nas histórias coletadas, é que a palavra "fim" é muito utilizada para demarcar o término das narrações. A maioria das narrativas dos estudantes da 6 . $^{a}$ série é finalizada com essa palavra, por exemplo, "A menina ficou feliz. FIM." (15 anos), e "ele colocou sua rede e dormiu nela. Fim" (12 anos), indicando que o mesmo recurso de fechamento é utilizado independente da idade como ocorreu com a fórmula inicial.

Outro aspecto observado, mas em menor escala, é que muitas histórias finalizam com um conselho ou explicitam a moral, mas não são fábulas como nestes enunciados: (a) nós devemos ajuda a natureza (15 anos, 6. ${ }^{a}$ série); (b) Moral: Pedrinho aprendeu que se todos fizerem sua parte podem melhorar o mundo e após isso descançarem. (13 anos, $7 .^{\text {a }}$ série).

Quanto a essa primeira dificuldade, concluiu-se que: muitos estudantes não estabelecem distinção entre conto de fadas e fábulas mesmo alguns deles estando no final do ensino fundamental; a maioria dos textos é narrativa, mas não há clareza quanto ao gênero discursivo pelo qual o autor optou. Segundo Fang:

O conhecimento de gêneros é fundamental para o desenvolvimento da competência comunicativa que envolve a codificação de mensagens de formas bastante específicas e previsíveis dentro de determinados contextos comunicativos. Pesquisadores (Chapman, 1994; Cope \& Kalantzis, 1993; Kamberelis, 1998) sugeriram que a construção de conhecimento de diversos gêneros e as situações retóricas tipificadas que constituem e são constituídas por esses gêneros é uma tarefa do desenvolvimento primário de jovens crianças como eles aprendem a ler e escrever $(1999, \text { p. } 2)^{5}$.

\footnotetext{
${ }^{5}$ Knowledge of genres is critical for the development of communicative competence, which involves the encoding of messages in fairly specific and predictable ways within particular communicative contexts. Scholars (Chapman, 1994; Cope \& Kalantzis, 1993; Kamberelis, 1998) have suggested that gaining knowledge of diverse genres and the typified rhetorical situations that constitute and are Constituted by these genres is a primary developmental task for young children as they learn to read and write.
} 
Portanto, um trabalho sistemático de leitura e análise de diferentes gêneros do eixo do narrar e das próprias produções dos alunos pode levá-los a compreender o estilo e a composição do gênero a fim de, a partir da depreensão dessas características, produzir, avaliar e corrigir seus próprios textos.

A segunda dificuldade identificada no corpus analisado diz respeito à estrutura da narrativa (STEIN; GLENN, 1979; SCLIAR-CABRAL; GRIMM-CABRAL, 1984) considerando os seguintes aspectos: formas de início, cenário, apresentação do personagem, uso do discurso direto e modos de finalizar a narrativa.

Dois recursos foram usados pelos autores para iniciar o texto. Como já informado anteriormente, a fórmula inicial "era uma vez" foi a expressão utilizada por mais da metade dos estudantes, ressaltando-se que os que cursavam a sexta série foram os que mais se valeram dela, sendo identificada em $68 \%$ dos textos nesta série. Segundo Scliar-Cabral (1991), esse recurso permite o fictício e sugere a produção do conto de fadas que, como já analisado, não foi o que ocorreu entre os estudantes. O outro recurso foi o uso de um indicador temporal, especialmente um advérbio, dos quais se destacam os seguintes: um dia (18\%); em um belo dia (11\%); em um dia ensolarado (8\%); em uma tarde ensolarada (5\%) e uma manhã (1\%). A indicação da temporalidade permitiu que os estudantes situassem o leitor $\mathrm{e}$ descrevessem o cenário o qual é condição para o desenvolvimento do sistema de episódios conforme Stein e Glenn (1979).

De acordo com esses autores, vários estados ou atividades podem ocorrer dentro da categoria de cenário. Analisando as narrativas produzidas, há os que introduzem o cenário apenas indicando a temporalidade conforme analisado no parágrafo anterior, mas existem narrativas cujo espaço é descrito logo em seu início. Entre as opções dos estudantes, encontram-se: jardim; floresta; bosque; quintal; referências a casa: área de sua casa, perto de sua casa; jardim de casa.

O cenário, dentro da teoria aqui proposta, também introduz o personagem apresentando seu estado ou atividade. Nas cenas sugeridas para a produção da narrativa, o personagem é um menino. Os estudantes escolheram diferentes formas para nomeá-lo. A maioria dos estudantes $(45 \%)$ preferiu atribuir o nome de uma pessoa sendo o personagem chamado de João em grande parte das histórias o que remete também aos contos clássicos (João e Maria, João e o pé de feijão). Outro 
modo de introduzir o personagem foi o uso de artigo indefinido seguido de substantivo comum (24\%) como em: "um garoto", "um menino”, "um menininho". Isso sinaliza a introdução de uma informação nova no texto que deverá depois ser recuperada com artigo definido, pois será uma informação dada, permitindo ao leitor estabelecer a relação entre os referentes. Em outros textos, encontra-se recurso de artigo seguido de substantivo, complementado por uma adjetivação (14\%) como em: "um garoto que era apaixonado por árvores enormes; um menino que gostava de plantar árvores e cuidar delas; uma criança que gostava de descansar; um menino que era muito bonitinho; um menino muito estudioso; um garoto muito feliz; um menino lenhador". Nesses casos, o autor, além de apresentar uma informação nova, introduz o personagem na forma de seu estado, já estabelecendo relação com as ações que serão apresentadas ao longo dos episódios na narrativa. Outro modo de apresentar o personagem foi o uso de substantivo comum (10\%) como "menino" e "pequeno menino" sendo que neste há também a informação sobre o estado do personagem. O recurso de menor uso (7\%) foi o de apresentar o nome antecedido de artigo definido como em "o garoto" e "o menino". Isso indica a necessidade do estudo dos anafóricos bem como do uso e função de artigo definido e indefinido em narrativas o que pode ser realizado através da análise linguística de fábulas que se valem, em sua maioria, desse recurso linguístico.

O uso do discurso direto aparece como regra opcional na proposta de ScliarCabral e Grimm-Cabral (1984), o que nos levou a identificar tal recurso. Nas narrativas analisadas, não é comum o uso do discurso direto, havendo apenas quatro ocorrências. Em três delas o aluno usa o recurso apenas uma vez, ao escrever "-Pronto, agora sim_" o autor, aluno da 6." série, marca o diálogo com travessão. Já o aluno da $8^{a}{ }^{a}$ série marca o discurso direto usando, além do travessão, aspas: "Essa árvore vai ser uma lenha das boa!". O uso do diálogo em todo o texto se faz presente na produção de uma aluna da 8 . $^{a}$ série cujo título é a "grande surpresa" no qual há uso do travessão, mas não há recuo no início parágrafo:

"Certo dia, Henrique estava no mercado com sua mãe, e viu que fora dele tinha várias pessoas, dando sementes e árvores pequenas, e perguntou:

- Mãe, o que é tudo isso? 
E sua mãe respondeu

- É que hoje é o dia da árvore e todos os anos eles fazem isso.

- Posso pegar uma? - perguntou Henrique.

- Claro que sim meu filho - respondeu sua mãe com rapidez.

Chegando em casa colocou uma roupa velha e foi pedir ajuda para seu pai.

- Pai?

Ninguém respondeu, e então sua mãe chegou e disse:

- Meu filho seu pai foi viajar e só volta daqui a 15 dias

Triste, ele foi para o quintal e plantou a árvore.

Ele deu carinho, ele deu água e amor, e pensando ele falou:

- Quando papai chegar vou fazer uma surpresa para ele.

Sua árvore cresceu e cresceu, todos os dias ele foi cuidar de sua grande amiga.

Passados 15 dias, Henrique colocou uma rede nela e deitou esperando seu pai chega e Ihe mostra sua grande surpresa".

Para encerrar a análise da estrutura narrativa, serão apresentados os cinco caminhos pelos quais os estudantes optaram para encerrar suas narrativas. Setenta e três delas finalizam apresentando alguma ação, mas não são necessariamente uma consequência direta em relação aos episódios que a antecederam e que foram narrados pelo autor. Os estudantes relacionam a ação com o último quadro apresentado no comando da produção no qual o personagem está deitado em uma rede amarrada entre duas árvores. Algumas narrativas são ampliadas e relatam o que aconteceu "[...] e sempre à noite deitava em sua rede e olhava as estrelas; botou nas duas árvores uma rede para descansar e comer sorvete"; outras apenas descrevem a cena "[...] ele ia lá para tirar uma sonequinha"; "[...] lá na rede descansando". Alguns estudantes, como já informado, sentiram necessidade de garantir o final da sua história e escreveram a expressão "fim", muitas vezes seguida de pontos de exclamação "Fim!!!" ou sem pontuação ou em letra maiúscula, tanto junto à última sentença como separadamente na última linha assemelhando-se ao que ocorre ao final de um filme. Constatou-se que apenas 11 dos 164 textos apresentam estado final como identificado nestes: "assim adormeceu feliz por ter feito algo de bom; e passou ali o resto de suas tardes de verão". Retomando o que se analisou na parte referente aos gêneros, algumas narrativas encerram com um conselho, mas não são fábulas. Quando isso ocorre, o tema é a natureza e as recomendações são expressas como nestes enunciados: "é importante cuidar da natureza"; "por isso que é bom cuidar das árvores um [dia] podem precisar delas"; 
"então se você ajuda o meio ambiente ele ajuda você". Esse tipo de final quebra a relação de causalidade, deixando de apresentar uma consequência direta como descrito na regra 13 de Stein e Glenn (1979), conduzindo, assim, a narrativa para a última regra que diz respeito à reação. A fórmula de encerramento "eles viveram felizes para sempre" está presente em apenas quatro das narrativas, entretanto elas não utilizam a fórmula inicial típica dos contos de fadas "era uma vez". Outro aspecto observado é que a narrativa poderia ser encerrada sem a fórmula como neste caso: "E alguns anos depois as duas arvores cresceram e ele amarrou uma rede para dormir. E ele viveu feliz para sempre". O autor usa a relação de temporalidade para o crescimento das árvores, descreve a cena do último quadro e, para garantir o fechamento, lança mão da fórmula de outro gênero textual.

A respeito da coesão textual, é importante considerar que os estudantes têm dificuldade para conectar as partes da história. A maioria das narrativas apresenta um único parágrafo e os autores usam principalmente esses elementos coesivos: $e$, que, depois disso, então. De acordo com Stein e Glenn (1979), o episódio é uma sequência comportamental completa incluindo eventos internos e externos os quais terão uma resposta como consequência. Por isso, a inter-relação episódica precisa ser formalizada e para isso sugere-se, na regra 3 , o uso de e, então e causa. Concordamos que

\begin{abstract}
aprender a escrever de forma eficaz implica aprender a ordenar uma série de sentenças, ligadas por propriedades comuns para formar um todo integrado. Consequentemente, aprender a escrever implica manusear dispositivos coesivos adequadamente. Os elementos coesivos estabelecem uma relação semântica entre um elemento de um texto e alguns antecedentes, o que é crucial para a sua interpretação. (YDE; SPOELDER, 1990, p 187-188) ${ }^{6}$.
\end{abstract}

Além dos quatro articuladores mencionados anteriormente, as narrativas apresentam, em menor número, o uso de porque, até, quando, mas. Dentre os conectivos, foi possível observar que o $E$ foi empregado em 128 narrativas (considerando apenas um uso em cada narrativa). "O terceiro tipo de relação que

\footnotetext{
${ }^{6}$ Learning to write effectively implies learning to order a series of sentences, linked by common properties to form an integrated whole. Consequently, learning to write handle cohesive devices appropriately. A cohesive ties is a semantic relation between an element in a text and some antecedent that is crucial to its interpretation.
} 
pode existir entre dois episódios é uma relação E. Esta relação indica que dois episódios ocorrem simultaneamente" (STEIN; GLENN, 1979, p.21) ${ }^{7}$. Entretanto, nas narrativas analisadas, identificaram-se quatro diferentes funções e sentidos para o articulador E: (a) adicionar elementos textuais como neste enunciado: "Quando ele voltou, com uma rede e cordas em suas mãos, amarrou cada extremidade da rede em cada árvore..."; (b) progressão temporal cujo valor é similar ao dos articuladores como: então; em seguida, depois disso e assim: "A mãe de Pedro segurou a rede e ajudou ele a amarrar sua rede nas árvores". (c) relações de causa e consequência, nesse caso, o coesivo E é equivalente aos articuladores de causa, por exemplo, porque ou de consequência (por isso, assim, consequentemente) como neste excerto da narrativa: "Um dia, Fernando aprendeu na escola como plantar uma árvore e decidiu colocar o que aprendeu em prática”. (d) Conclusão e acabamento: "Marcos estava tão feliz com o que ele tinha, ele decidiu estender uma rede entre duas árvores, e descansou feliz".

Ainda no que se refere à coesão textual, analisamos os anafóricos tendo em vista sua importância para recuperar o referente. Analisando as narrativas escritas pelos estudantes, observamos que 93 delas usam o pronome sujeito, principalmente "ele" para recuperar o referente. Como em português é possível omitir o sujeito, 31 narrativas fizeram uso da elipse, por exemplo: "então comprou outra árvore" no qual o autor omitiu o pronome pessoal de terceira pessoa do singular ele que pode ser facilmente identificado pela desinência verbal. Outros anafóricos usados foram: substantivo comum (o menino), nome próprio (João) e pronome (sua), entretanto, esses recursos linguísticos foram identificados em apenas sete textos. Para exemplificar os usos de distintos anafóricos, selecionamos a narrativa, "O menino João", de uma aluna da $6 .^{a}$ série que, além da elipse do ele, apresenta diferentes modos de retomada do referente um menino chamado João os quais estão identificados em negrito e sublinhado:

"Certo dia um menino chamado João comprou uma árvore e plantou ela perto de sua casa. Mas ele queria mais uma então comprou outra árvore e plantou ela do lado da outra árvore, João colocou dois nomes muito

\footnotetext{
7 The third type of relation that can exist between two episodes is an AND relationship. This relationship describes two episodes which occur simultaneously.
} 
esquisitos que são: Batata e Amendoim. Todos os dias o menino ia regar a plantas, que cresceram e se tornaram lindas árvores. João teve uma ideia de colocar uma rede entre as duas árvores. E sempre que ele vinha da aula, ele ia lá na rede pra tirar uma sonequinha.

Fim!"

Já anunciamos, na parte teórica, que a característica fundamental de uma história é a presença da relação de causalidade na estrutura narrativa (MAR, 2004). A análise das produções dos alunos sinalizou que não há compreensão clara da relação entre causa e consequência. A maioria das histórias é baseada nas cenas que acompanhavam o comando da produção textual e nas ações do personagem, o que aponta para a ausência de uma série de regras conforme o modelo de Stein e Glenn (1979). No que tange ao aspecto aqui focado, os autores asseveram que "a relação horizontal entre dois episódios ligados pela relação ENTÃO indica a falta de nexo causal direto. O segundo tipo de relação que liga dois episódios é a relação de causa. A relação de causa implica uma relação causal direta [...]”. (STEIN; GLENN, 1979, p.19) ${ }^{8}$.

Em alguns textos, como pode se observar nos excertos que seguem, foi identificada uma tentativa de estabelecer tal relação, mas não houve desenvolvimento: (a) "ele regava, colocava adubo. Até que elas cresceram"; (b) "Eu regava a árvore todo dia, as duas árvores foram crescendo e crescendo até virar uma árvore madura"; (c) "Já que as árvores estavam grandes, o menino Hugo resolveu montar uma rede para passar os dias"; (d) "e então a árvore estava grande e bonita, ele colocou uma rede e descansou". Em (a), por exemplo, há uma relação de causa-consequência entre regar, adubar e crescer, mas não há uma articulação desse fato com as ações desenvolvidas pelo personagem que levariam, então, a uma consequência direta ao final da narrativa. As relações nos enunciados (b) e (c) se aproximam de (a) no que tange ao crescimento das árvores. Os enunciados (c) e (d) apresentam como consequência a rede como um espaço de descanso para o personagem, mas não houve conflito ou mesmo uma sequência de planejamento para a aplicação do plano. Tal diagnóstico foi fundamental para o planejamento das

\footnotetext{
${ }^{8}$ The horizontal relationship between two episodes connected by the THEN relation indicates the lack of direct causality. The second type of relation which connects two episodes is the CAUSE relation. The CAUSE relation implies a direct causal [...].
} 
atividades realizadas no início das ações do subprojeto em sala de aula que centrou na análise das relações de causalidades em narrativas.

Em alguns casos, foi possível perceber também que os textos apenas descreviam as cenas do comando, o que demanda uma investigação sobre a internalização do esquema narrativo e o seu desenvolvimento por parte desses alunos. A capacidade de compreender narrativas novas (e produzi-las), segundo Scliar-Cabral (1991), se deve a dois aspectos primordiais: observância de uma estrutura canônica subjacente que permite compreender o desenrolar da narrativa no espaço e no tempo e presença de categorias e seus elos formalizados em sistemas semióticos. Esse desenvolvimento e conhecimento estão relacionados com as práticas de letramento das crianças e adolescentes em seus diferentes contextos. O que se pode observar no contexto escolar, durante a ação dos bolsistas, é que poucos alunos estão inseridos em práticas de leitura e escrita em casa e que, na escola, não há participação em eventos de letramento que ajudem a consolidar as práticas letradas o que pode explicar as produções escritas do diagnóstico.

Além do apresentado até aqui no que tange à causalidade, ainda foram identificados as seguintes dificuldades: as histórias não apresentam problema para ser resolvido; as narrativas são curtas; algumas histórias apresentam sentenças soltas não havendo articulação entre elas; há narrativas com apenas um episódio. Também esse levantamento de problemas serviu de base para o trabalho junto aos alunos, levando os bolsistas participantes do subprojeto a compreenderem como avaliar textos e, partindo deles, planejar ações que auxiliem na ampliação dos conhecimentos linguísticos e textuais.

Até aqui analisamos as narrativas no que tange à sua estrutura e dimensão estilística sendo esses aspectos os contemplados em ações pontuais para o trabalho junto aos alunos em cada turma segundo os seus conhecimentos construídos acerca de narrativas e suas dificuldades. Vale ressaltar que ações foram pontuais para cada turma, tendo em vista que houve um diagnóstico por grupo e sujeito, pois o objetivo era promover uma intervenção na produção de gêneros do eixo do narrar, o que foi se desenvolvendo ao longo da atuação junto aos alunos em cada escola. 
Para encerrar a análise, pontuamos quatro problemas que dizem respeito à grafia de palavras: (a) os estudantes, embora estejam nos anos finais do ensino fundamental, escrevem como falam, ou seja, realizam uma transcrição da fala como foi identificado em: derrepente, plantala, quintau, cuchilo, pocas. Há aqui problemas de juntura intervocabular, alteamento de vogal, monotongação, os quais revelam que há necessidade de ensino sistemático e reflexivo sobre as diferenças entre língua oral e escrita. (b) Os estudantes não consideram ou não conhecem as regras dependentes do contexto fonético ou morfológico como em: estavão, relachamdo, irria, penssou. Nesses casos, o conhecimento dos princípios do sistema alfabético se faz necessário a fim de que as regras sejam internalizadas, facilitando a grafia de palavras cujo contexto auxilia na previsão do grafema a ser selecionado para representar o fonema. (c) Não ocorreu a internalização de palavras cujo contexto é competitivo, ou seja, pode haver a seleção de mais de um grafema para representar o fonema, por isso constitui a maior dificuldade ortográfica na aprendizagem do sistema escrito. São exemplos a grafia de descançar, relachando, jente. Em casos como o do fonema $/ \mathrm{s} /$, que apresenta o maior número de possibilidades de conversão, como ocorreu na grafia de "descançar", "é necessário selecionar no léxico mental ortográfico o item que emparelhe semântica e morfossintaticamente com a forma fonológica" (SCLIAR-CABRAL, 2003, p. 151). Situações dessa natureza podem ser resolvidas e compreendidas se houver um ensino da gramática que considere: o papel do significado quando os dois itens forem da mesma classe gramatical; a morfologia, especialmente, a derivação.

\section{DAS APRENDIZAGENS SOBRE A PRODUÇÃO ESCRITA E A FORMAÇÃO DE PROFESSORES}

Neste artigo, tivemos como objetivo analisar os dados provenientes da coleta inicial das produções de narrativas dos anos finais do ensino fundamental dos participantes do subprojeto de Letras. Optamos por este viés, pois a avaliação, no que se refere à produção textual, é um tema que tem sido pouco discutido na formação inicial de professores, especialmente, a diagnóstica tendo em vista que esta direciona as ações docentes para as particularidades de cada turma e permite 
identificar os saberes já construídos pelos alunos e suas dificuldades as quais foram sinalizadas ao longo deste texto. Entretanto, antes de apresentá-las, contextualizamos descrevendo o subprojeto e a metodologia bem como discutindo a base teórica que nos permitiu compreender a natureza das narrativas e ter, assim, um olhar para a avaliação dos textos produzidos na escola.

Sinteticamente, a análise identificou que as narrativas apresentam três aspectos a serem considerados para o trabalho em sala de aula: (a) há introdução da cena e dos personagens com expressões linguísticas convencionais de início; (b) a maioria dos textos apresenta uma ação que sugere um esboço ou tentativa de uma situação-problema; (c) o desfecho está presente, porém não é explicitado como a situação-problema foi resolvida. O que isso significa? Que antes de um trabalho com gêneros discursivos, no nosso caso, os do eixo do narrar, é preciso desenvolver a base comum que aproxima as narrativas: o esquema narrativo o qual, em nossa proposta, é o descrito por Stein e Glenn (1979) e revisto por Scliar-Cabral e GrimmCabral (1984). Tais conhecimentos permitiram definir as categorias a serem analisadas em cada texto produzido pelos alunos, verificando se eles tinham internalizado ou não o esquema narrativo, que conhecimentos linguísticos haviam utilizado para poduzir seus textos e, principalmente, como estabeleciam as relações de causalidade. A delimitação das dificuldades por turma direciona o trabalho de forma singular, partindo dos conhecimentos prévios a fim de construir novos conhecimentos que permitam produzir um gênero do eixo do narrar que se caracterize como tal.

No que se refere ao planejamento das ações didáticas direcionadas pelo diagnóstico, é imperativo organizar um plano de trabalho em sala de aula durante todo o ano, selecionando os objetos de ensino e de aprendizagem, os objetivos já delineados pela proposta curricular como é o caso das escolas nas quais atuamos, considerando, também, os avanços e as necessidades de cada turma e dos alunos que a constituem.

Por fim, diante do analisado, concluímos que além de uma intervenção colaborativa com cada grupo de estudantes para ajudá-los a refletir sobre o modo como organizam suas narrativas, é necessária a produção de material como jogos, atividades reflexivas, análise linguísticas de gêneros discursivos do eixo do narrar o 
que requer uma seleção de textos que auxiliem na depreensão das regras que se distribuem ao longo de uma narrativa.

As experiências desenvolvidas junto às turmas mostraram um avanço significativo no que tange à estrutura narrativa, havendo a internalização da maioria das regras através de atividades de leitura, análise linguística e produção de diversos gêneros discursivos do eixo do narrar, mas isso é assunto para novos textos tendo em vista que aqui nos limitamos a analisar o processo inicial de escrita e atuação dos participantes do subprojeto de Letras. Portanto, finda o texto, mas não a investigação ou mesmo a ação docente, essa é contínua e requer uma formação que ultrapassa o tempo da graduação e o espaço da universidade.

\section{OTILIA LIZETE DE OLIVEIRA MARTINS HEINING}

Doutora em Linguística pela Universidade Federal de Santa Catarina (UFSC). Professora do Curso de Letras e do Mestrado em Educação da Universidade Regional de Blumenau (FURB).

\section{REFERÊNCIAS}

BAMBERG, M. Development of linguistic forms: German. In: BERMAN, R.A; SLOBIN, D.I. (eds.) Relating events in narrative: a crosslinguistic development study. Hillsdale: Erlbaum, 1994, p. 189-238.

BARTLETT, F. C. Remembering: a study in experimental and social psychology. Nova York: Cambridge University Press, 1932, p. 1-11.

BERMAN, R. A; SLOBIN, D.I. (eds.) Relating events in narrative: a crosslinguistic development study. Hillsdale: Erlbaum, 1994, 739 p.

BERMAN, R. A. Narrative competence and storytelling performance: how children tell stories in different contexts. Journal of narratives and life history, n.5. p. 285-314, 1995.

BUARQUE, L. et al. Avaliação do desempenho da rede pública escolar do estado de Pernambuco na área da linguagem. Estudos em avaliação educacional, n. 5, p. 95106, 1992.

BRUNER, J. Life as narrative. Social research. Nova York, v. 71, n.3, p. 691-710, 2004.

CANDIDO, A. et al. A personagem de ficção. 2. ed. São Paulo: Perspectiva, 1968, $124 \mathrm{p}$. 
FANG, Z. The Development of Literate Potential in Literature-Based and Skills-Based Classrooms. Literacy Teaching and Learning, v. 4, n. 1, p. 1-25, 1999.

FIVUSH, R; HADEN, C. A. Narrating and representing experience: preschoolers' developing autobiographical accounts. In: VAN DEN BROCK, P. W.; BAUER, P. J.; BOURG, T. (org). Developmental spans in event comprehension and representation. New Jersey: Lawrence Erlbaum, 1997, p. 169-198.

FURB. Subprojeto de Letras. Blumenau, 2011,3 p.

GHEZZI, P. et al. The influence of age of listener on preadolescent's linguistic behavior. The psychological record, n. 37, p. 109-126, 1987.

HUDSON,J.; SHAPIRO, L. From knowing to telling: the development of children's scripts, stories, and personal narratives. In: McCABE, A.; PETERSON, C. (org.). Developing narrative structure. Hillsdale: Erlbaum, 1991.p. 89-136.

LINS E SILVA, M.; SPINILLO, A. Uma análise comparativa da escrita de histórias pelos alunos de escolas públicas e particulares. Revista brasileira de estudos pedagógicos, n. 79, p. 5-16, 1998.

MAR, R. A. The neuropsychology of narrative: story comprehension, story production and their interrelation. Neuropsychology. Dallas, v. 42, p. 1414-1434, 2004.

McCABE, A. et al. Comparison of personal versus fictional narratives of children with language impairment. American Journal of Speech-Language Pathology. Philadelphia, v. 17, p. 194-206, 2008.

PREECE, A. The range of narrative forms conversationally produced by young children. Journal of child language, n. 14, p. 273-295, 1987.

REGO, L.L. Descobrindo a língua escrita antes de aprender a ler: algumas implicações pedagógicas. Revista brasileira de estudos pedagógicos, n. 66, p. 5-27, 1985.

. A escrita de estórias por crianças: as implicações pedagógicas do uso de um registro linguístico. Revista de documentação de estudos em linguística teórica e aplicada, n. 2, p. 165-180, 1986.

RUMELHART, D. E. Notes on a schema for stories. In: BOBROW, D. G.; COLLINS, A. Representation and understanding: studies in cognitive science. Londres: Academic Press, 1975, p. 211-236.

SCHANK, R. C. The structure of episode in memory. In: BOBROW, D. G.; COLLINS, A. Representation and understanding: studies in cognitive science. Londres: Academic Press, 1975, p. 237-272. 
SCLIAR-CABRAL, L.; GRIMM-CABRAL, L. Caracterização das qualidades narrativas em pré-escolares. In: Ilha do Desterro: a bilingual journal of language and literature. Florianópolis, v.11, p. 56-74, 1984.

SCLIAR-CABRAL, L.; STOEL-GAMMON, C. Emergence of the reportative function in child speech. Trabalho apresentado no $4^{\circ}$ Congresso Internacional de Linguística Aplicada. Stuttgart, 1976, p. 389-398.

SCLIAR-CABRAL, L. Introdução à psicolinguística. São Paulo: Ática, 1991, 191 p. . Princípios do sistema alfabético do português do Brasil. São Paulo: Contexto, 2003, 263 p.

SHIRO, M. Genre and evaluation in narrative development. Journal of child language, n. 30, p. 165-195, 2003.

SPINILLO, A. G.;PINTO, G. Children's narratives under different conditions: a comparative study. British journal of development psychology, n. 12, p. 177-193, 1994.

STEIN, N. L.; GLENN, C. G. An Analysis of story comprehension in Elementary School children: a test of schema. In: FREEDLE, R. O. New directions in discourse processing. Norwood: Albex, 1979, p. 53-119.

TARDIF, Maurice. Saberes docentes e formação profissional. Tradução Francisco Pereira. 2. ed. Petrópolis, RJ: Vozes, 2002, 325 p.

YDE, P.; SPOELDERS, M. Cohesive ties in written narratives: a developmental study with beginning writers. In: HALLIDAY, M. A. K., GIBBONS, J.; NICGOLAS, H.

Learning, keeping and using language. Philadelphia, PA: John Benjamins Publishing Company. 1990, p. 187-204. 